\title{
OS SABERES E OS FAZERES CONSTRUIDOS NA SALA DE AULA DURANTE O ESTÁGIO SUPERVISIONADO
}

\author{
SHIRLANE MARIA BATISTA DA SILVA \\ Doutoranda em Educação na UFPI. E-mail: shir_mari@hotmail.com \\ BÁRBARA MARIA MACÊDO MENDES \\ Doutora em Educação pela UCE, professora do Programa de Pós-Graduação em Educação da UFPI. \\ E-mail: barbarammendes@ hotmail.com
}

\section{RESUMO}

Este artigo tem como objetivo geral investigar o Estágio Supervisionado do curso de Pedagogia, na perspectiva de análise dos saberes e dos fazeres construídos na regência de classe. Como objetivos específicos: caracterizar a prática pedagógica no estágio supervisionado no que concerne ao saber e ao fazer docente; descrever os saberes e os fazeres construídos na vivência do estágio supervisionado; identificar como o aluno estagiário relaciona os saberes construídos na academia com a prática pedagógica no estágio supervisionado. O Estágio Supervisionado deve ser o momento de formação que viabilize a produção de conhecimentos sobre a realidade da escola durante a regência de classe. É uma pesquisa narrativa e para produção dos dados utilizamos o questionário, o memorial e as rodas de conversa. Os dados foram analisados e interpretados com a técnica de análise de conteúdo, tomando como base Bardin (2009). A investigação foi realizada com alunas do sexto período do curso de Pedagogia do Centro de Estudos Superiores de Caxias/UEMA, matriculados na disciplina Estágio Supervisionado do ensino fundamental. O aporte teórico foi sustentado nos autores Pimenta e Anastasiou (2002), Veiga (2009), Tardif (2006), Pimenta e Lima (2004), Buriolla (2011), Mendes (2006), Brito (2011), Piconez (2007), entre outros. Os resultados do estudo apontam para a necessidade de reflexões e discussões mais aprofundadas sobre o saber, o saber ser e o saber fazer necessários à formação dos futuros professores, a fim de se estabelecer relações entre os saberes construídos na academia e os saberes construídos na prática de sala de aula durante o estágio supervisionado.

Palavras-chave: Estágio Supervisionado. Saber. Saber ser. Saber fazer. Prática pedagógica.

\section{THE KNOWLEDGE AND DOINGS BUILT IN CLASSROOM DURING THE SUPERVISED TRAINEESHIP}

\begin{abstract}
This article has as a general objective to investigate the Supervised Traineeship of the Pedagogy Course, the analysis perspective of knowledge and doings built in the class regency. As specific objectives: to characterize the pedagogical practice in Supervised Traineeship that concern to know and to do teaching; to describe the knowledge and doings built on the experience of Supervised Traineeship; to identify as the trainee student relates the knowledge built into the academic institution with the pedagogical practice in the Supervised Traineeship. The Supervised Traineeship should be a moment of formation that enables the production of knowledge about school reality during the class regency. It is a narrative research, to the production of data, the questionnaire was used, the memorial and the conversation circles. The data were analyzed and interpreted with the content analysis technique, based on Bardin (2009). The research was conducted with the students from the sixth period of the Pedagogy Course of Centro de Estudos Superiores de Caxias/MA (CESC-UEMA). The theoretical framework was sustained in authors Pimenta and Anastasiou (2002), Veiga (2009), Tardif (2006), Pimenta e Lima (2004), Buriolla (2011), Mendes (2006), Brito (2011), Piconez (2007), among others. The study of results points to a reflection and further discussion on knowledge, how to be and know-how of future teachers.
\end{abstract}


KEYWORDS: Supervised Traineeship. To know. Know how to be. Know how to do. Pedagogical Practice.

\section{Introdução}

A construção do ser professor não é apenas aquisição de técnicas e de conhecimentos que serão postos em prática, no contexto da escola e da sala de aula, mas, sobretudo, é o momentochave da socialização e da configuração do futuro profissional da educação. É nessa fase que o futuro professor tem oportunidade de avaliar se realmente a sua opção profissional corresponde ao seu ideal profissional, às suas aptidões e às suas expectativas de vida. É no estágio supervisionado que o aluno, futuro professor, experiencia o ser e o fazer docente da profissão.

Durante a regência de classe do aluno estagiário, ele constrói e (re)estrutura na prática o saber fazer, construindo a formação do ser professor. $\mathrm{O}$ aprender a ensinar vai se concretizando na medida em que o futuro professor vai articulando os conhecimentos adquiridos no decorrer de sua formação e de sua prática pedagógica, vivenciada cotidianamente na sala de aula, na vivência do estágio.

A partir dessa compreensão, surgiu o interesse em realizar um estudo sobre o Estágio Supervisionado no curso de Pedagogia. A escolha da temática na formação do pedagogo, saberes e fazeres construídos no espaço de sala de aula aconteceu em virtude de nossa experiência como docente da referida disciplina, no citado Curso, no Centro de Estudos Superiores de Caxias (CESC), da Universidade Estadual do Maranhão (UEMA).

Esse interesse se consubstanciou e se formatou a partir do questionamento: quais os saberes e os fazeres construídos pelos alunos estagiários na vivência do estágio supervisionado? Para norteamento do estudo, definimos como objetivo geral da pesquisa: investigar o Estágio Supervisionado do curso de Pedagogia do CESC, na perspectiva de análise dos saberes e os fazeres construídos na regência de classe. Como delineadores distributivos do objetivo geral, estabelecemos os seguintes objetivos específicos: caracterizar a prática pedagógica no estágio supervisionado no que concerne ao saber e ao fazer docente; descrever os saberes e os fazeres construídos na vivência do estágio supervisionado; identificar como o aluno estagiário relaciona os saberes construídos na academia com a prática pedagógica no estágio supervisionado; analisar os desafios e as dificuldades que acontecem durante o estágio supervisionado no contexto da sala de aula na escola campo.

Tomamos como técnicas e instrumentos basilares para produção de dados da pesquisa os questionários, as rodas de conversa e os memoriais que delinearam como aconteceu cada uma 
dessas etapas. Essa parte contempla, ainda, o cenário da pesquisa, o perfil das interlocutoras e o processo de sistematização e de análise dos dados. O aporte teórico foi sustentado nos autores Pimenta e Anastasiou (2002), Veiga (2009), Imbernón (2010), Tardif (2006), Gauthier (2006), Contreras (2002), Brzezinski (2002), Pimenta e Lima (2004), Buriolla (2011), Rios (2010), Mendes (2006), Brito (2011), Piconez (2007), entre outros.

Para alcançar os objetivos propostos em nosso estudo, selecionamos um aporte teórico que orientou e deu suporte à investigação, conduzindo para o desenvolvimento do estudo e, consequentemente, para a análise dos resultados da pesquisa empírica.

A fundamentação teórica que tem como base as discussões e as reflexões a respeito da formação de professores e dos saberes adquiridos durante o estágio é o que discutiremos no tópico formação do pedagogo e o estágio supervisionado a seguir. Após essa discussão evidenciaremos os caminhos trilhados na pesquisa, apontando também as técnicas e instrumentos para produção dos dados. Na ordem, mostraremos o cenário da pesquisa bem como os interlocutores envolvidos, para então apresentarmos as análises, discussões e interpretações dos dados. Em seguida, fecharemos o corpo do artigo com as conclusões e, por fim, relacionaremos as referências utilizadas no presente estudo.

\section{Formação do pedagogo e o estágio supervisionado}

As discussões sobre a trajetória do curso de Pedagogia têm sido aprofundadas, contextualizadas e ampliadas ao longo de mais de 70 anos em todo o país por autores como Libâneo (1990), Brzezinski (1996) e outros. Porém, ainda existem muitos estudos a serem realizados e muito a se discutir sobre a crise e as dificuldades enfrentadas por esse curso. Esses problemas têm relação direta com o processo de formação e sinalizam, também, para a necessidade de repensar e de rediscutir a formação do profissional formado por este curso.

O curso de Pedagogia foi instituído por ocasião da organização da Faculdade Nacional de Filosofia, da Universidade do Brasil, através do Decreto-Lei n. 1.190, de 4 de abril de 1939, tendo como objetivo formar bacharéis nas áreas das Ciências Humanas, Sociais, Naturais, Letras, Artes, Matemática, Física, Química e licenciados através da concepção normativa que alinhava todas as licenciaturas ao denominado esquema $3+1$, através do qual era feita a formação nas diversas licenciaturas para várias áreas.

Nesse prisma, título de bacharel seria conferido a quem cursasse três anos de estudos em conteúdos específicos da área - fundamentos e teorias educacionais -, e o título de licenciado que 
permitia atuar como professor aos que, tendo concluído o bacharelado, cursassem mais um ano de estudos, dedicados à Didática e à Prática de Ensino.

Com a homologação da Lei n. 4024/1961 e a regulamentação contida no Parecer do Conselho Federal de Educação CFE n. 251/1962, algumas pequenas alterações foram introduzidas no currículo do curso de Pedagogia. Manteve-se o esquema 3+1 e, em 1961, fixou-se o currículo mínimo do curso de bacharelado em Pedagogia, composto por sete disciplinas obrigatórias indicadas pelo CFE e mais duas escolhidas pela instituição - opcionais.

As disciplinas obrigatórias eram: Psicologia da Educação, Sociologia (Geral e da Educação), História da Educação, Filosofia da Educação e Administração Escolar. As optativas eram: Biologia, História da Filosofia, Estatística, Métodos e Técnicas de Pesquisa Pedagógica, Cultura Brasileira, Educação Comparada, Higiene Escolar, Currículos e Programas, Técnicas Audiovisuais de Educação, Teoria e Prática da Escola Média e Introdução à Orientação Educacional.

Esse mecanismo centralizador da organização curricular pretendia definir a especificidade do bacharel em Pedagogia e visava manter uma unidade de conteúdo, aplicável como critério para transferências de alunos, em todo o território nacional.

O curso de Pedagogia passou por grandes transformações após o parecer n. 252/69 CFE, que regulamentava o currículo mínimo, orientando para a formação de profissionais técnicoadministrativos, oferecendo habilitações em supervisor, orientador, administrador, inspetor, planejador e professor formado para o trabalho no ensino médio.

\section{O Estágio Supervisionado do Curso de Pedagogia do CESC}

Considerando o Manual da Dimensão Prática dos Cursos de Licenciatura, que é um instrumento orientador do processo de formação e de desenvolvimento acadêmico do estudante da UEMA, e que rege a Prática Curricular, o Estágio Curricular obrigatório e as atividades científicoculturais, o Estágio Curricular Obrigatório nos cursos de Licenciatura deverá oportunizar ao estudante condições propícias ao desenvolvimento de sua prática docente, mediante a regência de classe e intervenção sistematizada em situações que se apresentam no campo de estágio.

O Estágio Curricular obrigatório terá início na sala de aula da universidade, objetivando o repasse da fundamentação teórica e depois o estagiário será encaminhado à instituição de ensino, denominada escola campo de estágio. O estagiário assinará o termo de compromisso do estágio em conjunto com o Supervisor Técnico e a Direção da escola.

As atividades de estágio serão compostas de: 
1. Orientação e exercício teórico-metodológico específicos para planejamento e aulas simuladas, em classe da licenciatura.

2. Vivência no ambiente educativo em que serão realizadas atividades específicas do contexto educativo e a intervenção da pesquisa iniciada na prática curricular.

3. Encontro regulares em classe da licenciatura, para avaliação do desenvolvimento do estágio.

\section{Os caminhos trilhados na pesquisa}

Para concretizar a nossa pesquisa, realizamos uma investigação de natureza qualitativa, com ênfase metodológica nas narrativas. Para Richardson (2008), a pesquisa qualitativa pode se caracterizar como a tentativa de compreensão de atuações e de comportamentos. Segundo Oliveira (2008), a pesquisa pode ser entendida como um estudo de um determinado fato, objeto, grupo de pessoas ou atores sociais e fenômenos da realidade. Tomando como base as palavras da autora, esse é um procedimento que objetiva buscar informações precisas, concretas para explicar o significado e as características do contexto em que se encontra o objeto de estudo da pesquisa.

Assim, optamos por esse tipo de pesquisa porque acreditamos no que diz Oliveira (2008), que nas comunicações dos participantes da pesquisa existe uma relação dinâmica, viva, entre o mundo real, objetivo, concreto e o sujeito que será investigado.

Portanto, a pesquisa qualitativa coaduna-se com os objetivos propostos nesta investigação, haja vista que através da pesquisa qualitativa tivemos possibilidades de realizar a análise dos fenômenos indo além das aparências, explicitando os fatos relatados e evidenciando o que ficou nas entrelinhas.

A pesquisa qualitativa, com ênfase na narrativa, como recurso metodológico é frequentemente utilizada nas pesquisas educacionais como fonte de investigação, tornando a pesquisa narrativa, sobre professores em processo de formação, alvo de investigação e de vinculação das histórias vivenciadas no decorrer do processo de construção do saber, do saber ser e do saber fazer-se professor.

Quanto mais significativos forem os registros realizados numa narrativa, mais ricas elas se tornam. Os tipos de narrativas são inúmeros em sua diversidade, e nós os encontramos nos lugares mais variados. O ser humano sempre vai contar histórias que podem ser suas ou as de outra pessoa.

Essas considerações indicam que as narrativas realizadas neste estudo contribuiram para que os futuros professores socializem conhecimentos, troquem informações, reelaborem suas práticas pedagógicas, manifestem e veiculem seus saberes docentes, socializando conhecimentos e informações durante seu processo formativo. Para Prado e Soligo (2007, p. 48), as narrativas fazem 
parte da história do homem e desde os tempos mais remotos são para serem lidas, contadas e recontadas:

Assim, entendemos que o ato de narrar, de contar histórias é inerente ao próprio homem e que se as histórias forem utilizadas no contexto de investigação da formação profissional, contribuirão para que o professor se torne um pesquisador de sua própria prática. A utilização da narrativa como técnica e método de investigação tem construído espaço cada vez mais crescente como alternativa investigativa na formação de professores, tornando o professor pesquisador sujeito e objeto de sua própria investigação, proporcionando ao próprio professor um melhor entendimento de sua própria prática docente.

A narrativa funciona como pesquisa na medida em que, quem narra sua história socializa sua vida, suas experiências com o pesquisador, fazendo com que esse reflita e amplie sobre sua própria trajetória de formação e sua própria história de vida.

Por meio das narrativas uma pessoa relata fatos vivenciados ou presenciados ao longo de sua história, dando-lhes novas contextualizações, significações, reconstruindo a trajetória percorrida, reinventando e reorganizando as lembranças que realmente tiveram significados ou não no decorrer de sua vida de sua formação. A partir desse entendimento, realçamos o que diz Lima (2011), sobre as histórias de vida, que são para serem lidas, contadas e recontadas porque histórias de vida de professores possibilitam um olhar interdisciplinar imbricado na pesquisa biográfica. Assim, compreendemos que quando alguém se predispõe a contar ou escrever sua história de vida, de alguma forma estará expondo seus sentimentos, intimidades e emoções, muitas vezes evidenciando suas fragilidades, permitindo uma reflexão sobre sua própria história.

A escrita da narrativa nasce, inicialmente, de reflexões sobre suas aprendizagens e experiências circunscritas no percurso da vida, e implica num processo de reflexão, rememoração, construção e reconstrução dos fatos vivenciados, aproximando e distanciando o narrador de si mesmo. Segundo Souza (2008), o dia a dia do ser humano é marcado pela socialização de experiências, pelas narrativas que ouvimos e falamos. Surge daí a necessidade cada vez maior de se trabalhar com as autobiografias e com as biografias educativas em contextos de pesquisa na área educacional.

Narrar sua história de vida é expor sentimentos guardados e as narrativas de formação fazem parte do processo de construção desta formação, possibilitando a compreensão e reflexão da própria prática. Elaboradas de forma descritiva, as narrativas de formação conduzem o narrador a expressar seus sentimentos, falar de suas experiências, dos saberes e dos fazeres construídos ao longo de seu processo de formação. 
Nesse contexto, investigar os saberes e os fazeres construídos no estágio supervisionado pelos futuros professores, no espaço de sala de aula, através da utilização das narrativas, tornou-se um caminho para se conhecer quais as contribuições dessa experiência na formação do pedagogo, bem como uma oportunidade de repensar o estágio como espaço conectado ao projeto de constituição do professor no curso de Pedagogia.

Assim, a pesquisa qualitativa narrativa se constituiu no nosso estudo como um processo crítico-reflexivo importante, porque permitiu revelar experiências formativas no espaço da sala de aula através dos memoriais do estágio supervisionado e dos relatos feitos nas rodas de conversa, o que contribuiu ainda para se compreender como são construídos os saberes e os fazeres durante o estágio e os avanços e retrocessos que acontecem durante a construção e reconstrução destes saberes na regência de classe.

\section{Técnicas e instrumentos para produção de dados}

Os dados da pesquisa foram obtidos através de instrumentos/técnicas de produção de dados tais como: questionário, através do qual as interlocutoras traçaram seu perfil formativo e profissional; memorial do estágio supervisionado, no qual elas relataram suas memórias formativas; nas rodas de conversa, momento em que narraram espontaneamente as experiências e vivências da vida profissional.

\section{O Questionário}

Uma das técnicas escolhidas para produção de dados foi o questionário. Esse foi estruturado com questões abertas e fechadas, tendo como objetivo traçar o perfil biográfico dos sujeitos da pesquisa. As questões abertas objetivaram deixar as interlocutoras à vontade para responder de acordo com seus conhecimentos e informações, e as fechadas limitaram ou conduziram as interlocutoras a respostas de acordo com as informações solicitadas.

Para Richardson (2008, p. 189), a informação obtida por meio de questionários permite observar as características de um indivíduo ou grupo. Nesse sentido, usamos os questionários buscando coletar dados referentes às características das interlocutoras, no que concerne aos aspectos pessoais, estudantis e profissionais, bem como aspectos relacionados ao ingresso, à escolha no Curso e à construção dos saberes e os fazeres na sala de aula, durante o estágio supervisionado.

As respostas contidas no questionário nos conduziram a uma leitura flutuante dos dados, que segundo Bardin (2009) é uma visão inicial e superficial das informações. Essa leitura nos 
proporcionou uma visão geral das nossas interlocutoras e permitiu delinear o perfil formativo e profissional de cada uma.

\section{O Memorial}

Outro instrumento escolhido para subsidiar a construção dos dados da pesquisa foi o Memorial do Estágio Supervisionado. Pensar e repensar sobre a utilização de memoriais, como instrumento de pesquisa, sobre a vida dos professores é tarefa dos grupos de pesquisa preocupados com as questões relativas aos estudos sobre a pessoa do professor, as práticas docentes e a profissão de professor e que veem na pesquisa narrativa com utilização dos memoriais, um instrumento fecundo e um rico aporte teórico-metodológico.

Memorial é um dos instrumentos da pesquisa narrativa - uma tipologia da pesquisa qualitativa, focalizando as contribuições do processo de rememoração na formação de professores. Ao escrever, marcamos um encontro conosco, com nossas memórias, imprimindo reflexões profundas sobre nossa vida, nossas práticas, nossa história.

Ao entregar os memoriais fizemos algumas explicações sobre a importância da produção das memórias do estágio supervisionado para nossa pesquisa. Algumas interlocutoras ao receber os memoriais demonstraram certa curiosidade e ansiedade. Sentiram-se importantes ao perceberem como era grande o compromisso que iriam ter diante da realização da pesquisa. E que elas iriam precisar resgatar algumas informações que estavam guardadas na memória.

A memória é a capacidade que temos de guardar, registrar, resgatar informações, conhecimentos, sentimentos, emoções, dor, alegrias, tristezas, e demais sensações de colocá-las em evidência, quando sentimos necessidade de trazê-los à tona. Becker e Marques (2010) dizem que nossa memória é seletiva, apagamos aquilo que não achamos importante, guardamos na memória as informações que têm mais ligação com o que queremos lembrar. As situações que de alguma forma nos remetem a alguma coisa, fato ou a alguém que queremos trazer de volta. A memória organizase por meio do estabelecimento de relações. Sempre que precisamos de alguma informação, que está guardada no passado, resgatamos em nossas lembranças já adormecidas pelo tempo.

Ao narrar nossa história, (re)visitamos o passado, na tentativa de buscar o presente. Manifestamos no memorial emoções, medos, anseios, sentimentos guardados. Somos produtores de informações, narradores escritores, atores e personagem da história que narramos.

Esse entendimento deixa evidenciado que para algumas pessoas reviver suas memórias pode se tornar um verdadeiro desafio, já que temos que voltar no passado, resgatar nossas lembranças e experiências vivenciadas, fazendo um exercício contínuo e sistemático de escrever a própria 
história, revivendo o percurso de vida e refletindo sobre ela. Esse é um exercício de autoconhecimento de reflexão sobre si mesmo e esse exercício pode ser prazeroso ou não, pode trazer alegrias, provocar sorrisos, dor, tristeza, voltar ao passado em busca de recordações de sentimentos guardados na memória que para muitos nem sempre é algo fácil de realizar.

Nesse contexto, o trabalho de pesquisa realizado com as professoras em formação, utilizando o memorial do estágio supervisionado como instrumento de pesquisa, discute aspectos referentes à vivência pessoal em relação aos saberes e os fazeres construídos nesse período, mostrando que o processo de autorreflexão proporcionado pela proposta de rememoração, pode resgatar elementos importantes sobre a prática dos estudantes em suas vivências, favorecendo a compreensão de vários aspectos da vida profissional do futuro professor.

Escrever sobre os outros ou sobre alguma coisa para muitos é uma tarefa difícil que demanda tempo, disposição, habilidades e conhecimentos sobre o que se pretende escrever. Entretanto, para muitos escrever sobre si mesmo pode se tornar uma tarefa mais difícil ainda e necessita de exercício de reflexão, criatividade e autoconhecimento, principalmente, quando não se tem o hábito de se expressar através da palavra escrita. Mas se for um hábito construído ao longo da vida poderá contribuir muito com a prática profissional, tornando-se fonte de reflexão de construção e de aprendizado.

A utilização dos memoriais do estágio supervisionado oportunizou, as futuras professoras revisitar suas memórias, resgatando fatos ocorridos durante o processo de sua formação docente, o que pareceu difícil, no início, tornou-se uma oportunidade de reflexão e de reconstrução de conhecimento e formação.

\section{A Roda de Conversa}

As Rodas de Conversa realizadas consistiram na criação de espaços de diálogo, em que as estagiárias tiveram oportunidade se expressar, estimulando a construção do conhecimento de inovação e, principalmente, de reflexão, o que aconteceu através da problematização e da busca de inovações. Essa técnica possibilita a abertura de espaço de encontro, de discussão, de produção, de socialização de conhecimentos, de trocas de experiências vivenciadas durante o estágio, evidenciando as perspectivas e a instrumentalização dos futuros professores, para lidarem com as complexidades do cotidiano na sala de aula.

Tomamos como referência as corroborações feitas por Warschauer (2002), sobre a roda de conversa. A roda é mandala, é círculo, é movimento que induz e conduz a produção do conhecimento - não de um conhecimento qualquer, mas daquele que se registra, se elabora, se 
alicerça, se amplia e se reconstrói na somente dentro da roda, mais é o conhecimento próprio do ser humano que existe, sempre, em toda sua vida, tenha ele zero, cinco, dez ou oitenta anos de idade.

Entendemos, portanto, que a roda de conversa é importante e pode contribuir para a construção de conhecimentos significativos e também para a pesquisa numa abordagem qualitativa. Ela estabelece relação de análise e interpretação dos dados podendo viabilizar a compreensão sobre as potencialidades da investigação e perceber o processo investigativo, como oportunidade de formação e autoformação dos sujeitos que dela participam. As rodas de conversa são bastante utilizadas na área de ensino, como instrumento ou prática pedagógica para discussão e socialização dos conhecimentos dos alunos.

Partindo desse entendimento, escolhemos a roda de conversa como uma técnica a ser utilizada em nossa pesquisa, partindo do pressuposto que através das rodas realizadas durante o estágio supervisionado, as interlocutoras foram conduzidas de forma espontânea a uma fértil discussão sobre temas, que possibilitassem refletir acerca do processo formativo, o registro dos saberes e dos fazeres produzidos e mobilizados durante o estágio no contexto de sala de aula.

A cada roda de conversa realizada, percebemos que as professoras em formação foram ficando mais a vontade para expressar seus sentimentos, formatando assim, a ideia de que as rodas de conversa possibilitam aproximação, favorecem as discussões e fortalecem os elos de amizade e confiança entre as professoras em formação.

A pesquisa teve como cenário o Centro de Estudos Superiores de Caxias - CESC, da universidade Estadual do maranhão - UEMA. Tendo como lócus específico o curso de Pedagogia, Departamento de Educação - Disciplina Estágio Supervisionado das séries iniciais do ensino fundamental, que é oferecida no sexto período.

A escolha desse cenário de investigação deu-se pelo fato de sermos docentes dessa instituição e termos intenção de desenvolvermos um estudo voltado especificamente para o curso de Pedagogia - Disciplina Estágio Supervisionado, e por conhecermos as dificuldades que os alunos estagiários encontram na produção e aplicação dos saberes e os fazeres, que devem ser aplicados na vivência do estágio e, assim, poder melhorar nossa prática pedagógica contribuindo para o processo de saber e saber fazer de nossos alunos.

Para concretização da pesquisa foram selecionados oito estudantes do sétimo período do curso de Pedagogia que estavam cursando a disciplina Estágio Supervisionadodas séries iniciais do ensino fundamental. Até o momento da realização da pesquisa, as estudantes haviam cursado a disciplina Estágio Supervisionado da educação infantil. As interlocutoras foram selecionadas com base nos seguintes critérios: estar regularmente matriculadas no Estágio Supervisionado das séries 
iniciais do ensino fundamental; aderir voluntariamente à pesquisa e ter disponibilidade para participar da produção de dados.

O primeiro contato com as interlocutoras da pesquisa aconteceu no CESC, na sala B5 do curso de Pedagogia - local em que as referidas interlocutorasse encontravam estudando. Após a autorização da Direção do Centro, realizamos uma reunião na sala de aula cedida pela Direção do Curso. Nesse momento, aconteceu nossa apresentação e apresentação de nossa pesquisa. A princípio, explicamos os objetivos da investigação e os instrumentos que seriam utilizados para produção de dados.

$\mathrm{Na}$ oportunidade, aproveitamos para sensibilizá-los, evidenciando a importância da disponibilidade da colaboração das interlocutoras para produção dos dados, explicitando que elas não teriam nenhuma despesa financeira com a participação na pesquisa e reafirmamos o compromisso com o anonimato dos participantes. O convite foi estendido a todos os alunos do Curso, tivemos a adesão de 08 alunas que, espontaneamente, mostraram interesse em participar da pesquisa.

No intuito de garantir o anonimato de nossas interlocutoras, solicitamos sugestões para definição de codinomes para identificá-las no trabalho. Ficou definido que os codinomes seriam nomes de flores. Nossa escolha tomou como base o entendimento que nossas interlocutoras são graduandas e estão em processo de formação.

Relacionamos esse processo de formação, fazendo analogia entre nossas interlocutoras e as flores. As flores são vegetais, têm um ciclo de vida e são o início da reprodução, futuramente frutos e depois sementes, semeando novas flores. Nossas interlocutoras no estágio estão vivenciando a profissão, e estão construindo sua formação profissional, depois serão sementes produzindo e reproduzindo conhecimentos que serão socializados e compartilhados.

Os nomes das flores foram definidos à medida que a convivência com as interlocutoras foi acontecendo e pudemos observar um pouco das características de cada uma a ponto de compará-las e denominá-las daqui para frente com os nomes das seguintes flores: Orquídea, Rosa, Gardênia, Azaléia, Hortênsia, Tulipa, Margarida e Dália. Na sequência, apresentamos a caracterização do perfil biográfico de cada interlocutora do ponto de vista pessoal e profissional.

As interlocutoras pesquisadas totalizam oito mulheres. A faixa etária que elas estão situadas varia de 18 a 55 anos. Na ocasião da produção de dados para esta pesquisa, encontravam-se cursando a disciplina Estágio Supervisionado nas séries iniciais do ensino fundamental. Apenas uma interlocutora cursava, concomitantemente, outra graduação - Filosofia. 
Dos oito sujeitos pesquisados, três possuem experiência docente no ensino fundamental, e uma na Educação de Jovens e Adultos (EJA) e os outros quatro não possuem experiência docente, evidenciando que para muitos o estágio supervisionado é a única oportunidade de articular os saberes adquiridos ao longo do curso com o fazer pedagógico, numa relação de experimentação, de integração e de reflexão sobre a realidade profissional que será vivenciada durante a docência.

De modo geral, constatamos que todas as interlocutoras da pesquisa são pessoas que possuem características singulares e veem no ensino superior uma oportunidade de emprego e, consequentemente, melhorarem de vida.

Para o tratamento dos dados, consideramos os aspectos recorrentes encontrados nas narrativas, realizando as interpretações e inferências. A partir desses aspectos, e tomando como base o objetivo geral, os objetivos específicos e partimos para construção do nosso plano de análise ilustrado no Quadro 01.

\section{Quadro 1 - Plano de análise dos dados da pesquisa}

\begin{tabular}{|c|c|}
\hline OBJETIVOS ESPECÍFICOS & $\begin{array}{l}\text { ASPECTOS RECORRENTES } \\
\text { DAS NARRATIVAS }\end{array}$ \\
\hline $\begin{array}{l}\text { Caracterizar a prática pedagógica no estágio } \\
\text { supervisionado no que concerne ao saber e ao } \\
\text { fazer docente }\end{array}$ & $\begin{array}{l}\text { - Concepção do estágio supervisionado; } \\
\text { - A importância do estágio } \\
\text { supervisionado; } \\
\text { - Necessidade de orientação durante todas } \\
\text { as etapas do estágio supervisionado; } \\
\text { - O estágio como componente formativo. }\end{array}$ \\
\hline $\begin{array}{l}\text { Descrever os saberes e os fazeres construídos na } \\
\text { vivência do estágio supervisionado }\end{array}$ & $\begin{array}{l}\text { - Saberes adquiridos na formação; } \\
\text { - Saberes produzidos na vivência do } \\
\text { estágio supervisionado }\end{array}$ \\
\hline
\end{tabular}

Fonte: dados da pesquisa

A leitura dos dados nos conduziu a uma síntese sobre a construção dos dois eixos de análise, que apresentamos neste momento de maneira resumida e que, posteriormente, serão apresentados de forma detalhada no terceiro capítulo deste trabalho (Quadro 2).

\section{Quadro 2 - Eixos de Análise dos Dados da Pesquisa}

\begin{tabular}{l|l} 
Eixo 1: & Concepção de estágio supervisionado
\end{tabular} 
Saberes e fazeres construídos na prática pedagógica, durante o estágio

Eixo 2: supervisionado

Fonte: Memoriais e rodas de conversa

Tomando como base os eixos de análise dos dados obtidos através dos memoriais e das rodas de conversa, conforme exemplificado no Quadro 2, destacamos aspectos importantes da investigação, tais como: concepção de estágio supervisionado; saberes e fazeres construídos na prática pedagógica durante o estágio.

Após a construção e análise dos eixos, constatamos na pesquisa resultados que nos conduziu a uma reflexão mais contundente sobre o Estágio Supervisionado e sobre nossa postura enquanto docente dessa disciplina.

A seguir, apresentaremos os eixos de análise da investigação, delineando, a partir deste momento, um diálogo com as interlocutoras primando pelo intercruzamento das diversas vozes apresentadas nas narrativas.

\section{Eixo 1: Concepção de Estágio Supervisionado}

Delineamos, a partir deste momento, um diálogo com as interlocutoras primando pelo intercruzamento das diversas vozes apresentadas nas narrativas, destacando as diferentes concepções de estágio.

A partir dos relatos produzidos nos memoriais, percebemos que, para Margarida, o Estágio Supervisionado "não é somente uma etapa a ser cumprida e sim um modo de se familiarizar-se com o mundo que escolhemos.”. A interlocutora aponta sua concepção de estágio como uma etapa que não seria apenas o cumprimento de uma exigência curricular, mas um período de familiarização com a futura profissão.

Partindo desse pensamento, compreendemos por meio do olhar de Margarida, que durante o Estágio, o futuro professor irá vivenciar inúmeras situações particulares ao seu campo de atuação, e talvez por ser uma experiência nova, a interlocutora demonstra preocupação com as atividades do estágio, porém reconhece a importância dessa etapa na formação, ratificando que é uma oportunidade de viver o cotidiano da escola, que permite ao futuro profissional perceber dificuldades, vivenciadas nessa fase, captando afinidades e, num processo contínuo, construindo e consolidando sua formação profissional docente. 
A narrativa de Margarida pode ser mais bem compreendida quando recorremos a Melo e Naves (2012) ao explicitar que o exercício da docência não é algo simples. Trata-se de um fazer complexo que exige do professor formação para além do domínio do campo científico de sua área de formação e atuação. Apoiado nesse entendimento, percebemos que a importância e a necessidade do estágio supervisionado, como lócus de formação e de construção do saber ser e do saber fazer do professor, precisa tornar-se espaço formativo de produção, de reflexão, e de construção de conhecimentos.

Já para Gardênia a concepção de estágio é entendida como processo que favorece ao aprendizado discente. Em razão disso, Gardênia, diz: " $O$ estágio deveria ser supervisionado e não fiscalizado, e, às vezes, nem fiscalizado". Onde deveria haver orientações, sugestões, acontece dessa forma "errou aqui, concerta ali". De acordo com Gardênia, o estágio deve favorecer o aprendizado do discente.

Mesmo tendo essa concepção, nossa interlocutora tece críticas a maneira como essa fase é conduzida, Gardênia afirma que o estágio é fiscalizado, e ainda acrescenta "[...] às vezes, nem fiscalizado.”. A interlocutora, com essa colocação ressalta a necessidade de um acompanhamento, de uma orientação. Não havendo as orientações e as sugestões, que são necessárias ao desenvolvimento do estágio, ele fica "solto" não assumindo a característica de supervisionado.

O entendimento de Gardênia, ao apontar o estágio como uma etapa de aprendizado, faz-nos compreender a importância do estágio como um momento de construção de conhecimentos, que se relacionam com a atuação profissional e, portanto, precisa ser devidamente orientado e supervisionado. A interlocutora ressalta a relevância de um trabalho de acompanhamento por parte dos professores de estágio, das ações discentes, e assim evitar o "errou aqui, concerta ali”, como ela expressou.

Diante dessa problemática, Melo e Naves (2012, p. 35) corroboram dizendo "que se torna oportuno reavaliar os saberes que são importantes na constituição da docência". É preciso romper com a cultura do "ensino porque sei", para "ensino porque sei e sei ensinar". Podemos perceber, ainda, na fala da interlocutora, o descompasso existente entre o professor orientador do estágio e o estagiário, evidenciando a frustração existente em relação à efetivação do acompanhamento do estágio.

As interlocutoras Dália e Azaleia, em suas narrativas, ressaltam a importância do estágio supervisionado como espaço formativo. Dália, ao dizer que: "O estágio nos permite colocar em prática os saberes adquiridos na formação e vivenciar situações que apareceram em nosso percurso profissional.”. Azaleia corrobora dizendo que: “[...] no estágio colocamos em prática nosso 
aprendizado em relação à profissão.”. Na concepção das interlocutoras, o estágio é o momento de colocar em prática os saberes e os fazeres adquiridos durante a formação inicial e vivenciar experiências comuns ao seu futuro campo de atuação profissional. Essa concepção reitera a importância do estágio na construção dos saberes e os fazeres necessários à formação e ao exercício profissional.

Nesse contexto, percebemos que durante o estágio, o graduando tem oportunidade de viver a profissão, assumir a regência de sala de aula experimentando as diferentes situações e os desafios da docência. De acordo com Pimenta (2004), o estágio, como espaço formativo e eixo curricular central nos cursos de formação de professores, possibilita que sejam trabalhados aspectos indispensáveis à construção da identidade, dos saberes e das posturas específicas ao exercício da profissão docente, possibilitando a produção de saberes que promovam uma formação de professores, pautada na formação holística do futuro professor.

Outra concepção semelhante é exposta por Orquídea: “O estágio permite vivenciar realmente a profissão do professor, o educar/ensinar, e deve estar de acordo com as ações éticas, aberta à reflexão sobre nossa atuação na escola.”. Nossa interlocutora declara que é durante o estágio que o graduando inicia sua vivência na profissão, no movimento "educar/ensinar". Acrescenta a importância dos pressupostos éticos e da reflexão sobre a prática. Orquídea nos apresenta um aspecto muito importante que é a reflexão. Sobre essa temática, Alarcão (2005, p. 41) afirma que a noção de professor reflexivo, baseia-se na consciência da capacidade de pensamento e reflexão que caracterizam o ser humano como criativo e não como mero reprodutor de práticas que lhe são exteriores.

A interlocutora Hortênsia vincula o estágio à relação entre os saberes específicos e pedagógicos e relata: "O estágio permite ao estagiário compreender como os saberes da teoria se concretizam na prática.”. Na concepção da interlocutora o estágio é a vivência que articula teoriaprática. Nesse sentido, Buriolla (2011, p. 93) diz que a teoria deve estar vinculada às necessidades práticas, a teoria é prática na medida em que determina as ações como guia de ação, ao esclarecer os objetivos, as possibilidades, o conhecimento da realidade social e as forças sociais.

Nos escritos de Mendes (2011), fica evidenciada a existência de lacunas, no que diz respeito à teoria e à prática, que impedem o licenciando de perceber as questões inerentes à escola, ao ensino e à aprendizagem.

Nas memórias da interlocutora Rosa, o estágio supervisionado passa por etapas técnicas que conduzirão o professor a vivenciar a prática do ser professor: "O estágio supervisionado é uma prática que inicia pela observação da prática pedagógica dos professores e permite o futuro 
profissional vivenciar a atuação profissional como professor.”. Vale lembrar que o estágio acaba tornando-se uma oportunidade que o aluno professor tem para vivenciar, experimentar em um ambiente concreto, as mais diversas situações de ensino-aprendizagem que acontecem no contexto de sala de aula, por meio da observação, da participação e da regência de classe. É o lócus em que a aproximação da prática se concretiza proporcionando uma visão mais ampla do saber ser, do saber fazer-se professor.

A interlocutora Tulipa deixa claro, em suas palavras, que é no estágio supervisionado que realmente acontecem os verdadeiros desafios do saber e do saber fazer do professor quando deixa evidenciada na sua fala que: “[...] é no estágio que nos deparamos com a realidade que iremos vivenciar.”. Para Brito (2011), o estágio supervisionado proporciona a aproximação do estagiário com a escola campo e, principalmente, com as diferentes situações de ensinar.

Nessa perspectiva, Maciel e Mendes (2011) em seu escrito, sobre o estágio supervisionado, corroboram assinalando que essa etapa se caracteriza como um momento indispensável na formação. Essa atividade formativa propicia a experiência nas diversas situações de ensinoaprendizagem e nos desafios da prática pedagógica.

As palavras de Tulipa são ainda referendadas por Buriolla (2011), quando diz que se há a intenção de realizar um estágio, que dê condições ao aluno para se preparar efetivamente [...] ele deve ter oportunidades que lhe possibilite participar de um campo de experiência, de maneira que possa vivenciar uma situação social competente, que lhe permitirá uma revisão constante desta vivência e o questionamento de seus conhecimentos, habilidades, visões de mundo etc.

Segundo Maciel e Mendes (2012), o estágio supervisionado caracteriza-se como o lócus de reflexão e ação sobre aspectos teórico-práticos que favorecem o processo ensino-aprendizagem de maneira que se concretizam atendendo as necessidades do processo de formação. Essa atividade formativa precisa ser constituída pelas ações e práticas que demandam reflexão, construção e encontro com as realidades social, educacional e escolar, além da compreensão de que através do estágio, o aluno professor terá oportunidade de vivenciar e realmente tornar-se professor.

\section{Eixo 2. Saberes e fazeres construídos na prática pedagógica durante o Estágio Supervisionado}

Para refletir sobre os saberes e os fazeres dos professores, devemos considerar as diversas experiências e vivências na sala de aula. Segundo Maciel (2012 p. 45), “[...] os saberes docentes constituem os professores como atores individuais e os agregam à prática profissional, adaptando-a e transformando-a.". 
Nessa perspectiva, ser professor implica em conhecer e dominar saberes para produzir conhecimentos. Gauthier (2006) apresenta uma concepção de ensino como espaço de mobilização de vários saberes, que formam uma espécie de reservatório, no qual o professor deve se abastecer para poder ensinar e se posicionar nas diversas situações de sua prática docente. Assim, de posse de saberes e de fazeres diversificados, o professor estará apto a repassar conhecimentos e ter uma prática docente coerente, que atenda aos objetivos propostos pela sua prática, embora nem sempre o fato de ter conteúdo conduza o professor a uma prática em que o saber ser e o saber fazer-se educador caminham em uma mesma direção. A partir deste momento, analisamos as falas das interlocutoras do Eixo 2.

Ao analisar o Eixo 2 e dialogar com as interlocutoras, percebemos que para Margarida, o estágio supervisionado é o momento de vivenciar a prática profissional e que essa vivência possibilita refletir sobre a atividade profissional de maneira coerente, contribuindo para o exercício da docência: “[...] é justamente no estágio, na prática, que poderemos, através da reflexão, buscar contribuir na maneira justa e eficaz com nossa prática. [...] e através de um trabalho coerente ser capaz de aplicar os diferentes saberes em diferentes situações.”. Portanto, o estágio possibilita aprender, refletir e entender a docência como responsabilidade social.

Margarida faz, ainda, um desabafo, deixando claro que ser professor não é tarefa fácil, e ainda complementa que o estágio se apresenta como uma sequência de dificuldades a serem superadas: "[...] cada dia de estágio vencíamos uma barreira [...]", transparece em seu relato a imagem negativa da profissão, resultante da insegurança, dos medos e dos anseios característicos das novidades que se apresentam todos os dias na sala de aula, do despreparo acadêmico para enfrentamento dos desafios do cotidiano da sala de aula.

Mesmo diante das dificuldades, a interlocutora não demonstra desejo de desistir, deixando claro que fez investimento pedagógico em sua prática, procurando despertar nos alunos a vontade de aprender: “[...] não era uma atividade monótona, trabalhávamos de forma diferenciada, com vídeos, dinâmicas de grupo, mas nada disso era o suficiente, isso me causava aflição, pois meu desejo era obter êxito.”. Sabemos que ser professor é tarefa que requer uma habilidade profissional muito grande para lidar com as diferentes situações de dificuldades encontradas na escola.

$\mathrm{Na}$ maioria das vezes, os alunos apresentam déficit de aprendizagem muito grande, e níveis de aprendizagem incompatíveis em relação ao seu ano escolar. As condições de trabalho são limitadas e muitas vezes o estagiário se sente só, sem poder compartilhar seus medos, anseios e expectativas, prejudicando, assim, o processo ensino-aprendizagem. Mesmo diante de todas as 
dificuldades enfrentadas, ficou evidenciado na fala de Margarida o desejo de ser professora, constituir uma carreira e ser bem sucedida.

A partir do depoimento de Gardênia, pudemos perceber que os saberes e os fazeres "[...] da prática são construídos no cotidiano no [...]". Nesse sentido, Oliveira (2010), ao falar sobre a construção dos saberes, diz que o professor enfrenta o mesmo desafio que qualquer aprendiz para iniciar seu ofício, construindo e exercendo seu saber cotidianamente na sala de aula, experimentando a difícil arte de ensinar. Rios (2010) diz que preparar aula, realizar o exercício da docência é, para o professor, uma experiência que requer o domínio e o exercício de vários saberes que deverão ser postos em prática.

Gardênia, ao falar da performance e do perfil do professor, afirma: "A performance dos professores são construídas no estágio supervisionado, onde é desenhado o perfil profissional do docente.”. Durante o estágio supervisionado, o professor iniciante tem oportunidade de construir, de experimentar o desafio da profissão, de se ver na prática simultânea de ensinar e aprender, concomitantemente, delineando, assim, sua construção docente. Para Rios (2010, p. 53), "[...] ser professor é uma profissão. Mas é no efetivo exercício de sua profissão que o professor recebe a denominação de docente, particípio presente - aquele que está desenvolvendo um processo de ensinar".

Nossa interlocutora continua sua narrativa, lembrando-se da importância de refletir sobre os saberes e os fazeres: “[...] é importante refletirmos sobre os saberes e os fazeres pedagógicos, muito embora construídos de forma fragmentada, se conseguir montar o quebra-cabeça, então, não será difícil planejarmos baseados nos conhecimentos adquiridos no decorrer do curso.”. Com essa fala, Gardênia sinaliza a necessidade de refletir sobre os saberes e os fazeres pedagógicos construídos ao longo do curso, deixando evidente a fragmentação dos saberes e as lacunas existentes em sua formação. Essas lacunas se evidenciam na falta de domínio de conteúdo, na dificuldade de estabelecer relação entre os saberes teóricos e os saberes práticos e, principalmente, na aplicação dos saberes necessários ao fazer-se professor.

Nessa perspectiva, lembramos que, segundo Pimenta e Lima (2004, p. 101), “[...] os estágios, de maneira geral, acabam por se configurar em atividades distantes da realidade concreta das escolas, resumindo-se, muitas vezes, a miniaulas na própria universidade e em palestras proferidas por profissionais convidados”. Embora diante de todos os problemas evidenciados e das fragmentações existentes em sua formação, Gardênia analisa suas dificuldades mostrando as possibilidades de contorná-las. Compreendemos, a partir da fala da interlocutora, que mesmo 
enfrentando muitas dificuldades, o estágio é uma oportunidade de construção e de reconstrução de saberes, os saberes da experiência profissional, que consolidam outros saberes inerentes à profissão.

Dália deixa claro que não tem dificuldades em relacionar o saber ser e o saber fazer-se professora. Por ter experiência com a escola e com a sala de aula e, portanto, ser uma atividade que faz parte de sua rotina, ela enfatiza: “[...] não tive problemas nem dificuldades em realizar meu estágio, isso porque já havia passado por esse processo no curso de magistério.”. O que não impede que a interlocutora também pare para refletir sobre seus saberes e sua prática pedagógica, haja vista que o Estágio Supervisionado é um espaço formativo que permite tanto ao professor iniciante como ao professor experiente vivenciar situações complexas, antes invisíveis, construindo, assim, a compreensão de aspectos relacionados a seu próprio processo de formação, e de aprendizagem de seus alunos.

Nesse sentido, Pimenta e Lima (2004) enfatizam que o estágio, para professores alunos que já exercem o magistério, tem seu sentido e significado a partir da natureza do trabalho docente que requer constante revisão das práticas, no sentido de tornar o professor um sujeito que constrói conhecimentos.

Para Orquídea, o estágio foi a primeira oportunidade de articulação dos conteúdos teóricos adquiridos ao longo do Curso com sua prática em sala de aula: "[...] o estágio também me proporcionou oportunidade de testar na prática, o aprendizado teórico que tive ao longo do Curso.”. A partir dessa compreensão, entendemos que através do estágio supervisionado, o estagiário terá oportunidade de se aproximar da escola e das situações de ensinar e aprender. Estabelecendo, assim, elos de conhecimento entre a escola, a sala de aula, os saberes adquiridos e a prática docente e, também, no contato com a escola e com a sala de aula construir saberes da experiência e consolidar esses saberes, principalmente, os pedagógicos.

Hortênsia mostra que as experiências proporcionadas pelo estágio supervisionado fomentam reflexões entre os conhecimentos teóricos e os saberes práticos aplicados na sala de aula: “[...] foi através das experiências do estágio, vividas em sala de aula que nós, futuros professores e profissionais da área docente, podemos refletir sobre os saberes práticos, mediante os saberes teóricos, pois estar de frente a uma sala de aula é ser responsável pela mediação do conhecimento.”. Sabemos das dificuldades que são inerentes ao estabelecimento e à cristalização do exercício de colocar em prática os saberes adquiridos durante o curso, já que, na maioria das vezes, esses conhecimentos são estudados de forma mecânica, descontextualizada da realidade e da vivência dos alunos. Tais práticas não proporcionam uma reflexão e uma aprendizagem crítica, nem uma formação que possa contribuir para o crescimento holístico do aluno-professor, relegando-o à 
condição de mero reprodutor de informações, provocando um descompasso entre a teoria e a prática.

Embasada nessa afirmação, tomamos como base as palavras de Mendes (2005, p. 176), a qual assevera que formar professores sem considerar os aspectos práticos da formação para o exercício de aprender, vivendo experiências, refletindo sobre o ser, o fazer e o saber "[...] não consolida o entendimento da relação teoria e prática, como eixo significativo de aprendizagem pela reflexão [...]". Assim, a articulação que deve existir entre os conteúdos teóricos e a prática, que será vivenciada durante o estágio supervisionado, configura-se como algo essencial ao processo formativo do futuro professor. Porque é, na vivência do estágio, que o aluno, futuro professor, experiencia o ciclo docente (observação, planejamento, regência de classe, avaliação) e percebe no seu fazer as limitações das aprendizagens, o qual reexamina o seu pensar e o seu agir profissional.

É possível encontrar pontos convergentes nas narrativas das interlocutoras Rosa, Tulipa e Azaleia, no que diz respeito à construção dos saberes e os fazeres edificados durante o estágio supervisionado. Em suas considerações sobre os saberes construídos na prática pedagógica com o estágio supervisionado, Rosa enfatiza: "O estágio permitiu articular os saberes construídos ao longo do curso, permitindo ao acadêmico construir métodos para ensinar e aprender.”. Ao realizar o estágio, o futuro professor mobiliza vários saberes para produzir conhecimentos que serão repassados durante seu exercício profissional. Conforme pontuam Pimenta e Lima (2004), os conhecimentos e as atividades que embasam a formação dos futuros professores devem objetivar que esses se apropriem de instrumentos teórico-metodológicos para compreender a escola, os sistemas de ensino e as políticas educacionais.

Ainda para Rosa, "Os saberes e os fazeres fazem parte da nossa vida como educadoras, e permite equilíbrio no exercício da prática pedagógica do professor.”. O estágio supervisionado configura-se como um campo de experiência, de vivência de situações concretas, tornando-se essencial à formação do futuro professor, possibilitando a execução do exercício prático da profissão docente e a articulação dos conhecimentos teóricos com os conhecimentos práticos. Segundo Pimenta (1995, p. 53), “[...] a atividade teórica é que possibilita, de modo indissociável, o conhecimento da realidade e o estabelecimento de finalidades para sua transformação". Mas produzir tal transformação, não é suficiente somente com a atividade teórica, é preciso atuar na prática.

Nessa mesma linha de pensamento, Tulipa fala da relação existente entre professor, que ora se constitui aluno e ora se constitui docente, em um processo dinâmico de ensinar e aprender: “Os saberes e os fazeres contribuem para aprender e ensinar, nós que somos discentes, aprendemos a ser 
docentes.”. A formação do ser professor acontece de maneira processual, gradativa. Não se aprende a ser professor da noite para o dia, mas em um processo de construção e de (re)construção de saberes, primando pela superação de obstáculos que irão surgir durante essa caminhada, pois é na busca da superação das dificuldades que se constrói, edifica-se, cristaliza-se a formação do saber ser e do saber fazer docente.

Azaleia, ao dar ênfase sobre o estágio supervisionado, comenta: "O estágio supervisionado é de grande importância, para nossa formação como futuros professores, onde podemos aplicar os conhecimentos adquiridos na academia e as habilidades da prática.”. Nessa perspectiva, o estágio deve ser um espaço de produção de conhecimentos adquiridos na academia e um processo de criação e de recriação do pensamento reflexivo, não devendo se limitar à pura e simples transferência e aplicação de teorias ou conteúdos, tornando-se fomentador de uma prática pedagógica reflexiva.

\section{Conclusão}

Considerando as análises dos dados, percebemos que as interlocutoras anseiam por uma formação mais consistente e assistida, em que se destaca o valor da prática reflexiva como elemento de análise e de reflexão do professor. O termo reflexão é abordado como condição essencial à formação crítica do professor e com um novo objetivo para a formação docente. O ensino reflexivo e os professores reflexivos nos remetem a perceber que, apesar de algumas atitudes e predisposições pessoais dos professores, existem destrezas ou habilidades que os docentes devem dominar para concretizar esse modelo de ensino. O conhecimento e o domínio do saber ser e do saber fazer docente são fundamentais para que os professores possam ensinar e contribuir para a formação daqueles que estão em fase inicial de construção de conhecimentos.

As concepções de formação de professores precisam partir da ótica de que os cursos de formação não podem mais conduzir o ensino como uma atividade que acontece através da transmissão pura e simples de conteúdos prontos. $\mathrm{O}$ atual contexto formativo exige que as práticas docentes contemplem uma formação solidificada na construção, (re)construção e formatação dos saberes dos professores, preocupando-se como esses são mobilizados e construídos no cotidiano escolar. O estágio pode proporcionar ao futuro professor a oportunidade de através de uma prática efetiva, reflexiva, conduzir o futuro professor à construção prática dos conhecimentos.

Nessa perspectiva, as discussões, em torno da disciplina Estágio Supervisionado, têm se tornado objeto de investigação nas pesquisas educacionais, considerando que muitos autores têm mostrado a necessidade de se delinear novos rumos para o desenvolvimento do estágio 
supervisionado. Diante dessa premissa, faz-se necessário desenvolver e aplicar novas concepções da referida disciplina. Entre esses autores, Piconez (1994, p. 16) argumenta que "[...] o objetivo do Estágio Supervisionado é o preparo do licenciando para o exercício do magistério em determinada área de ensino ou disciplina". E os saberes e os fazeres construídos ao longo do Curso e durante o Estágio Supervisionado possibilitam ao futuro professor experimentar o saber ser e o saber fazer-se professor.

Ao estudar a relação dos saberes construídos na academia e relacionar esses saberes com a prática de sala de aula durante o estágio, possibilita-nos entender que os diferentes saberes são construídos, mobilizados e ressignificados durante toda vida. A partir dos registros das interlocutoras que foram expressos nos memoriais, ficou nítido que há necessidade de se experienciar, na prática, os saberes e os fazeres construídos durante o estágio, mesmo considerando as dificuldades encontradas durante sua execução.

\section{Referências}

ALARCÃO, I. Professores reflexivos em uma escola reflexiva. 4. ed. São Paulo: Cortez, 2005.

BARDIN, L. Análise de conteúdo. Lisboa: Edições 70, 2009.

BECKER, F.; MARQUES T. B. I. (Org.). Ser professor e ser pesquisador. Porto Alegre: Mediação, 2010.

BRITO, A. E. Professores experientes e formação profissional: evocações... narrativas...e trajetórias. Linguagens, Educação e Sociedade, Teresina, 17, p. 29-38, jul./dez. 2007.

(Re)discutindo a formação de professores na interface com o estágio supervisionado.

Revista Iberoamericana de Educación n. 56/2. Page 2. 2011. 15/9/11. Disponível em: <http://www.rieoei.org/deloslectores/3908Edna.pdf>. Acesso em: 12 jun. 2012.

BURIOLLA, M.; A. F. Estágio Supervisionado. São Paulo: Cortez, 2011.

BRZEZINSKI, I. Pedagogia, Pedagogos e Formação de Professores - busca e movimento. Campinas, São Paulo: Papirus, 1996

CONTRERAS, J. A autonomia de professores. São Paulo: Cortez, 2002.

ARAÚJO, R. D. de. O estágio supervisionado no curso de Pedagogia da Uespi: articulação teoria-prática na formação docente. Dissertação (Mestrado em Educação). 135 f. Programa de PósGraduação em Educação, Centro de Ciências da Educação, Universidade Federal do Piauí, 1999. 
GAUTHIER, C. [et al], PEREIRA, F. Tradução. Por uma teoria da pedagogia: pesquisas contemporâneas sobre o saber docente. Ijuí: Ed. UNIJUí, 2006

LIBÂNEO, J. C. Didática. São Paulo: Cortez, 1990.

LIMA, M. da G. S. B. Autobiografias de professores e formação: releitura de uma tese. In: MENDES S. J. A. de C.; LIMA, M. da G. S. B. L. (Org.). Formação, prática pedagógica e pesquisa em educação: retratos e relatos. Teresina: EDUFPI, 2011.

MACIEL, E. M. O estágio supervisionado como espaço de construção do saber ensinar. 106f. Dissertação (Mestrado em Educação). Universidade Federal do Piauí. Teresina: UFPI, 2012.

MENDES, B. M. M. A prática de ensino e o estágio supervisionado na construção de saberes e competências didático-pedagógicas: o caso da UFPI. Tese de doutorado (Doutorado em Educação) 310 f. Programa de Pós-Graduação em Educação. Núcleo de educação, Currículo e Ensino. Universidade Federal do Ceará, 2005

MELO, G. F. NAVES, M. L. de P. (org). Didática e docência universitária. Uberlândia: EDUFU, 2012

OLIVEIRA, M. M. de. Como fazer pesquisa qualitativa. 2. ed. Petrópolis-RJ: Vozes, 2008.

OLIVEIRA, M. M. de. Como fazer pesquisa qualitativa. 2. ed. Petrópolis-RJ: Vozes, 2010

PICONEZ, S. C. B. (Coord). A prática de ensino e o estágio supervisionado. Campinas, São Paulo, Papirus, 1994

PIMENTA, S. G.; LIMA, M. S. L. Estágio e docência. São Paulo: Cortez, 2004

PIMENTA, S. G.; Estágio na formação de professores: unidade teoria e prática? São Paulo: Cortez, 1995

PRADO, G. do V. T. (Org.). Narrativas docentes: Trajetórias de trabalhos pedagógicos. In: Saberes docentes: narrativas em destaque. Campinas, São Paulo: Mercado de Letras, 2007

RICHARDSON, R. J. [et al]. Pesquisa social: métodos e técnicas. 3. ed. São Paulo: Atlas, 2008

RIOS, T. A. Compreender e ensinar: Por uma docência da melhor qualidade. 8. ed. São Paulo: Cortez, 2010.

SOUZA, E. C. ; MIGNOT, A. C. V. (org.). Historias de vida e formação de professores. Rio de janeiro: Quartet: FAPERJ, 2008 
TARDIF, M. LESSARD, C. MAGALHÃES, L. Tradução. O ofício de professor. 2 ed. Petrópolis, RJ: Vozes, 2008

WARSCHAUER, C. A roda e o registro: uma parceria entre professor, aluno e conhecimento.Rio de Janeiro: Paz e Terra,2002.

Recebido em: 01.06.2016

Aceito em: 18.08.2017 